\title{
The automated psychological evaluation system (APES)
}

\author{
DAVID R. EVANS \\ The University of Western Ontario, London, Ontario, Canada \\ H. DOMINIC COVVEY \\ University Hospital, London, Ontario, Canada \\ LOUIS GLIKSMAN \\ The University of Western Ontario, London, Ontario, Canada \\ KAL CSAPO \\ London Psychiatric Hospital, London, Ontario, Canada
}

and

G.F.D. HESELTINE

University Hospital, London, Ontario, Canada

\begin{abstract}
This paper describes the rationale, design, cost, and extensions related to an automated test battery. Increased manpower, speed of service, lower cost, accuracy, and quality of reporting support the use of the system. The liability of failure to maintain and update the system is noted. Design considerations concerning mode of testing, tests included, and method of programming are discussed. The relative cost of automated and conventional testing is examined. Future extensions to the system are reviewed.
\end{abstract}

Several authors have argued for automation in the mental health field (viz. Glueck \& Stroebel, 1969; Hilf, 1972; Spitzer \& Endicott, 1969). To date, the major focus of this activity has been directed toward the initial interview and diagnosis (Endicott \& Spitzer, 1972; Hilf, 1972; Spitzer \& Endicott, 1969). While not yet a reality, it is fairly easy to envisage the full impact of automation in the mental health field (Spitzer \& Endicott, 1969). In the context of the above activities, progress has been made in the automation of psychological testing (Elwood, 1969; Fowler, 1969; Paitich, 1970. 1973). Psychological evaluation provides one form of data collection, in relation to mental health activities with a client. It is in this perspective that the present automated psychological evaluation system was developed.

In the past decade, there has been a contrasting increase in the demand for psychological services and a decrease in the number of trained psychologists (Fowler, 1969; Stuart, 1972). One solution has been to train technicians to perform many of the routine tasks of psychological practice (Fowler, 1967). An alternate and perhaps more promising solution has been to automate both psychological evaluation and therapy (Finney, 1966; Fowler, 1967, 1969; Hogan, 1971); further support for the development of automated psychological evaluation relates to its speed, lower cost, accuracy, and quality. Several authors have discussed the contrasting speed of automated evaluation over conventional evaluation (Finney, 1966; Fowler, 1968; Hedl, O’Neil, \& Hansen, 1973). Conceptually, the cost of computer assessment should be far less than the cost of the psychologist's time in conventional assessment. The comparative accuracy and quality of automated evaluation has also been noted (Finney. 1966; Hedl, O’Neil, \& Hansen, 1973; Linkerhoker \& McCarron, 1974).

Finney (1966) and Goldstein and Reznikoff (1972) have emphasized that the computer will, of course, only carry out those operations for which it is programmed (Finney, 1966; Goldstein \& Reznikoff, 1972 ). Hence, automated testing is only as good as the program, which is written to score, interpret, and report the results of testing. This problem, however, can be offset by continually revising the program in three major ways: (1) The program should be revised such that it more and more approximates, and finally perhaps surpasses, the type of report that a senior clinician would write. (2) As new norms, scales, and interpretive rules become available, these should be incorporated into the programs. (3) As a local data base is developed, local norms should be calculated, data should be collected (when possible) on a local "normal" sample, and local interpretive rules should be developed. The latter activity is rarely if ever carried out using conventional evaluation, but it is possible and desirable when an automated system is employed. 
One other caution concerning automated assessment relates to the tendency to be locked into a particular test or set of tests. Some tests may be of little value following initial use, while others may be replaced by new and better instruments. Hence, it is important to design a system such that tests can be dropped or added at any time.

The first consideration in designing an automated psychological evaluation system is the mode by which the client's data is input into the computer. Present methods for handling data input range from card input to on-line input using a computer terminal. Hedl. O'Neill, and Hansen (1973) used an on-line system to auminisier test items and input the ciient's responses to the computer. Thorough analysis of present on-line time-sharing systems suggests that they are capable of handling short, simple, single tests. However, when a complex battery of tests is employed, the following problems arise: (1) interaction with the computer is noticeably slow and irritating to the testee; (2) excessive computer core is employed at one time; and (3) the system is more costly than other methods. The most appropriate system when employing a complex battery of tests lies in the use of conventional test booklets with response forms designed for use with an optical scanner. The latter system is the one presently employed with APES.

Having decided upon the input mode, the next most important question is the selection of tests and the testing strategy. To date, a considerable number of psychological tests have been automated. The MMPI has received the most attention, and there are a number of automated systems which score, interpret, and report MMPI results (Finney, 1966; Fowler. 1967, 1968. 1969; Pearson, Swenson, Rome, Mataya, \& Brannick, 1964; Rome, Swenson, Mataya, McCarthy, Pearson, Keating, \& Hathaway, 1962; Swenson, Rome, Pearson, \& Brannick, 1965). Other objective personality tests that have been automated are the Sixteen Personality Factor Questionnaire (16PF) (Paitich, 1970, 1973; Eber, Note 1), the California Personality Inventory (Finney, 1966), and the Edwards Personal Preference Schedule (Woodson, 1969). Several projective techniques have been automated, e.g., the Rorschach (Piotrowski, 1964) and the Holtzman inkblot technique (Gorham, 1967). In the area of intellectual assessment, a number of tests have also been automated, for example, the Wechsler Adult Intelligence Scale (WAIS) (Elwood, 1969), the Raven Progressive Matrices (Paitich, 1970, 1973), and the WAIS-Clarke Vocabulary Test (Paitich, 1970, 1973). An exhaustive review of the literature, however, suggests that Paitich $(1970,1973)$ is the only author who has reported the automation of a system of tests.

In the Automated Psychological Evaluation System, a two-stage process of assessment is envisaged, involving an initial screening battery followed by more intensive assessment when indicated. Based on the senior author's experience while working with Paitich (1970) in the development of his automated system, the following tests were included in the initial screening battery: Raven Progressive Matrices, WAIS-Clarke Vocabulary Test, Trails, Minnesota Percepto-Diagnostic Test, and the 16PF (see Table 1). Following initial testing, a second strata of tests is being developed to evaluate specific aspects of a client's problem. Depending upon the nature of these tests, either the above format or an on-line format of administration will be employed. There are numerous tests that can be included in the second strata of tests. To date, only one, the MMPI has bee. programmed. A number of others, such as the Fear Survey Schedule, the Basic Personality Inventory, the Buss-Durkee Aggression Scale, and the Beck Depression Inventory, will also be included in this group of tests.

Another design question centers around the method of programming the battery, and each test in the battery. As it was anticipated that users might wish to use one, some, or all tests with a given client, the tests had to be programmed to allow for such a possibility. A main program was written to: enter the identifying and demographic data on the client, call the subprograms to score, interpret, and report those tests administered to the client, and print the header to the report. A separate subprogram was then written to score, interpret, and report each test. Modifications are being made to allow the user separately or in combination to score, profile, or report each of the tests.

The procedure followed with the MMPI was somewhat different due to its complexity. Most MMPI programs to date produce a report, such that the psychologist is unaware of the basis for any given

Table 1

Constituent Tests in the Screening Battery

\begin{tabular}{llrl}
\hline \multicolumn{1}{c}{ Test } & Function & Administration Time Mode of Administration \\
\hline Raven Progressive Matrices & Nonverbal Intelligence & $20-30 \mathrm{~min}$ & Self \\
WAIS-Clarke Vocabulary Test & Verbal Intelligence & $10-20 \mathrm{~min}$ & Self \\
Trail Making Test & Presence of Organicity & $5-10$ min & Technician \\
Minnesota Percepto-Diagnostic Test & Presence of Organicity & $5-10$ min & Technician \\
$16 \mathrm{PF}$ & Personality & $40-50 \mathrm{~min}$ & Self \\
\hline
\end{tabular}


Table 2

Estimated Costs of Automated and Conventional Testing in Dollars

\begin{tabular}{lcccc}
\hline & \multicolumn{4}{c}{ Mode of Testing } \\
\cline { 3 - 5 } Test & Psychologist I & $\begin{array}{c}\text { Psychome- } \\
\text { trist II }\end{array}$ & $\begin{array}{c}\text { Psycho- } \\
\text { technician }\end{array}$ & $\begin{array}{c}\text { Psychotech- } \\
\text { nician and APES }\end{array}$ \\
\hline Raven Progressive Matrices & 1.60 & 1.10 & .80 & \\
WAIS-Clarke Vocabulary Test & 1.60 & 1.10 & .80 & \\
Trails & 1.60 & 1.10 & .80 & \\
Minnesota Percepto-Diagnostic Test & 1.60 & 1.10 & .80 & \\
16 PF & 6.40 & $5.90^{*}$ & $5.60^{*}$ & $1.80^{* *}$ \\
Total & 12.80 & 10.30 & 8.80 & $4.00^{* *}$ \\
MMPI & 11.20 & $10.70^{*}$ & $10.40^{*}$ & 4 \\
\hline
\end{tabular}

*Must be interpreted by a psychologist but scored by the indicated person

${ }^{* *}$ Excluding administrative and computer system costs

statement in the report. Further, the majority of programs do not use all of the interpretive methods developed for the MMPI (Finney, 1967). In order to overcome these difficulties, separate subprograms were written to handle scoring, profiling, and interpreting the MMPI. To date, the scoring subprogram, the profiling subprogram, and interpretive subprograms for the Marks and Seeman (1963) and the Swenson (Pearson et al., 1964; Rome, Swenson, Mataya, McCarthy, \& Pearson, 1962) systems are operative. Other interpretive systems such as those of Gilberstadt and Duker (1965), Carson (1969), and Gynther (Gynther, Altman, \& Warbin, 1973) will be included in subsequent interpretive subprograms. At the present level of reporting, the psychologist still has to write the final integrated report. The computer output will provide information far in excess of that quickly available to the psychologist by conventional methods. Thus, dictation of a final inclusive report should take only 5-10 min. Only after considerable experience with the program will a subprogram be written to produce final complete reports on the MMPI.

In order to provide the reader some estimate of the comparative cost of automated and conventional testing, Table 2 is included. It should be stressed that APES was designed to allow psychologists to invest their time in therapeutic activities with their clients, rather than in assessment. An alternative use of this time is the delivery of service to a greater number of clients. These points have been noted by Finney (1966) and must be underscored in any discussion of relative cost. A further use of this service lies in the greater availability of psychological assessment for nonpsychiatric clients. Swenson and his colleagues (Pearson et al., 1964; Rome et al., 1972; Swenson et al., 1965) have demonstrated the wide use and acceptance of psychological evaluation with nonpsychiatric clients at the Mayo Clinic.

The following extensions of APES are seen as important: (1) The programming of additional, frequently used tests; (2) modification of the present reporting system based on feedback from users employing a reporting system similar to that indicated by Webb, Miller, and Fowler (1969); (3) continued updating of programs as new normative data becomes available, for example the new normative data provided by Wright and Hogan (Note 2); (4) collection of a data base on normal subjects in order to develop local norms for the tests; (5) development of further interpretive formulas and diagnostic statements based on local experience once other psychiatric data is available on testees; (6) the development of a predictive system concerning therapeutic intervention. For example, a number of authors have researched the feasibility of computer assignment of psychotropic drugs on the basis of standard patient data (Evenson. Altman, Sletten, \& Cho. 1973; Overall \& Hollister. 1972). Presumably, a set of formulas based on test items could be developed to predict the type of drug therapy for a given patient. Linkenhoker and McCarron (1974) have developed an automated system for prescribing therapeutic interventions with delinquents.

\section{REFERENCE NOTES}

1. Eber. H. W. Computer reporting of $16 P F$ data. Paper presented to the American Psychological Assuciation, Los Angeles, 1964.

2. Wright, M..\& Hogan, T. D. Personal communication. 1974.

\section{REFERENCES}

Carson, R. C. Interpretive manual to the MMPI. J. N. Butcher (Ed.), MMPI: Rescarch developments and clinical applications. New York: Mcliraw-Hill, 1969.

ELwood, D. L. Automation of psychological testing. American Psychologist. 1969, 24, 287-389.

Endicott, J., \& Spitzer, R. L. The value of the standardized interview for the evaluation of psychopathology. Journal of Personulity Assessment, 1972, 36, 410-417.

Evenson, R. C., Altman, H., Sletten, 1. W., \& Cho, D. W. Clinical judgement vs. multivariate formulae in assignment of psychotropic drugs. Joumal of Clinical Psychology, 1973. 29. 332-3.37.

Finney, J. C. Programmed interpretation of MMPI and CPI. Archives of General Psychiatry, 1966, 15, 75-82.

Finney, J. C. Methodological problems in programmed composition of psychological test reports. Behavioral Science, 1967 . 12. 142-152. 
Fowler, R. D. Computer interpretation of personality tests: The autonated psychologist. Comprehensive Psychiatry. 1967, 8, $455-407$.

Fowler, R. D. MMPI computer interpretation for college counselling. Jourmal of Psychology, 1968, 69, 201-207.

Fowlek, R. D. The current status of computer interpretation of psychological tests. American Journal of Psychiatry. 1969, 125iSuppl.), 21-27.

Gilberstadt, H., \& Duker, J. A hundbook for clinical and actuarial MMPI interpretation. Philadelphia, Saunders, $1 \% 5$.

Glueck, B. C., \& Stroerel, C. F. the computer and the clinical decision problem: Il. American Journal of Psychiatry, 1969. 125(Suppl.), 2-7.

Goldstein, A. M., \& Reznikoff, M. MMPI performance in chronic medical illness: The use of computer-derived interpretation. British Journal of Psychiatry, 1972, 120, 157-158.

Gorнam, D. R. Validity and reliability studies of a computer based scoring system for inkblot responses. Journal of Consulting Psychology, 1967, 31, 65-70.

Gynther, M. D.. Altman, H., \& Warbin, R. W. A new actuarial-empirical automated $\mathrm{MMPI}$ interpretive program: The 4-3/3-4 code type. Journal of Clinical Psychology, 1973. 29, 230-231.

Hedl, J. J.. ONeil, H. F.. \& Hansen, D. N. Affective reactions toward computer-based intelligence testing. Journal of Consulting and Clinical Psychology, 1973, 40, 217-222.

Hilf. F. D. Partially automated psychiatric interviewing-a research tool. Journal of Nervous and Mental Disease, 1972. 155. 410-418.

Hogan. R. A. Research thoughts toward a computerized therapy. Behavior Therapy, 1971, 2, 107-109.

Linkenhoker, D. D., \& McCarron, L. T. Computerized assessment programming (CAP): A prescriptive strategy for delinquents. Behavioral Science, 1974, 19, 254-259.

Marks, P. A., \& SEeman, W. Actuarial description of abnormal personality. Baltimore: Williams \& Wilkins, 1963.

Overall, J. E., \& Hollister, L. E. Decisions about drug therapy II: Expert opinion in a hypothetical situation. Behavioral Science, 1972, 17, 349-360.

Paitich, D. The Clarke automated examination and report (CAPER). Onturio Psychologist, 1970, 2, 304-314.

Paitich, D. A comprehensive automated psychological examination and report (CAPER). Behavioral Science, 1973. 18, $131-136$.

Pearson. J. S.. Swenson, W. M., Rome, H. P.. Mataya, P.. $\&$ Brannick. T. L. Further experience with the automated Minnesota multiphasic personality inventory. Mayo Clinic Proceedings. 1964, 39, 823-829.

Plotrowski. Z. A. Digital-computer interpretation of inkblot test data. Psychiatric Quarterly, 1964, 38, 1-26.

Rome, H. P., Swenson, W. M., Mataya, P.. McCarthy, C. E., Pearson, J. S., Keating, F. R., \& Hathaway. S. R Symposium on automated techniques in personality assessment. Mayo Clinical Proceedings, 1962, 37, 61-82.

Spitzer. R. L., \& Endicotr, J. Diagno II: Further developments in a computer program for psychiatric diagnosis. American Journal of Psychiatry. 1969, 125(Suppl.). 12-21.

STUART, R. B. The role of social work education in innovative human services. In F. W. Clark, D. R. Evans, \& L. A. Hamerlynck, Implementing behavioral programs for schools and clinics. Champaign, Ill: Research Press, 1972, 3-39.

Swenson. W. M., Rome, H. P., Pearson. J. S., \& Brannick, T. L. A totally automated psychological test experience in a medical center. Journal of the American Medical Association. 1965. 191. 925-927.

Webi. J. T.. Miller, M. L., \& Fowler, R. D. Extending professional time: A computerized MMPI interpretation system. Onturio Psychologist, 1969, 1. 256-271.

Woodson. M. I. C. E. PL/1 program to score the Edwards personal preference schedule (EPPS). Educational and Psychological Measurement, 1969, 23, 203. 